Check for updates

Cite this: RSC Adv., 2018, 8, 4773

Received 14th December 2017 Accepted 20th January 2018

DOI: 10.1039/c7ra13343

rsc.li/rsc-advances

\title{
Development of methodologies for the regioselective synthesis of four series of regioisomer isoxazoles from $\beta$-enamino diketones $\uparrow$
}

\author{
Raí G. M. Silva, ${ }^{a}$ Michael J. V. da Silva, ${ }^{a}$ Andrey P. Jacomini, ${ }^{a}$ Sidnei Moura, ${ }^{b}$ \\ Davi F. Back, ${ }^{c}$ Ernani A. Basso ${ }^{a}$ and Fernanda A. Rosa (D) *a
}

Four methodologies are reported for the regioselective synthesis of four series of regioisomer isoxazoles from cyclocondensation of $\beta$-enamino diketones and hydroxylamine hydrochloride. Regiochemical control was achieved by varying reaction conditions and substrate structure. The mild reaction conditions used to access 4,5-disubstituted, 3,4-disubtituted, and 3,4,5-trisubstituted regioisomer isoxazoles, as well as the pharmacological and synthetic potential of the products, make these novel methodologies very powerful.

\section{Introduction}

The isoxazole is an important framework because it is the core structure of remarkable medicinal products. ${ }^{1}$ For example, parecoxib (anti-inflammatory); sulfamethoxazole (antibiotic); leflunomide (antirheumatic); isocarboxazid (antidepressant); and risperidone (antipsychotic) (Fig. 1). Moreover, isoxazoles are masked 1,3-dicarbonyl equivalents, ${ }^{2}$ which serve as precursors for natural product synthesis, as for example tetracycline antibiotics. $^{2 c-h}$ For this reason, many synthetic methods have been reported for the synthesis of functionalized isoxazoles, ${ }^{3}$ including ring construction with functionalized precursors by 1,3-dipolar cycloadditions $^{4}$ or cyclocondensation ${ }^{5}$ reactions. One of the most popular, oldest, and most important methods for the synthesis of isoxazoles is cyclocondensation of 1,3-dicarbonyl with hydroxylamine (Claisen isoxazole synthesis). ${ }^{5 a-i}$ However, this approach suffers from frequent formation of a regioisomeric mixture of isoxazoles with poor selectivity, harsh reaction conditions, and a limited reaction scope. Furthermore, obtaining 4-substituted isoxazoles using this approach has been challenging. However, development of new cyclocondensation reactions has received little attention. Despite these challenges, our research group was motivated to develop a new methodology for synthesis of

${ }^{a}$ Departamento de Química, Universidade Estadual de Maringá (UEM), 87030-900, Maringá, PR, Brazil. E-mail: farosa@uem.br

${ }^{b}$ Laboratório de Produtos Naturais e Sintéticos, Instituto de Biotecnologia, Universidade de Caxias do Sul (UCS), 95070-560, Caxias do Sul, RS, Brazil

${ }^{c}$ Departamento de Quimica, Universidade Federal de Santa Maria (UFSM), 97110-970, Santa Maria, RS, Brazil

$\dagger$ Electronic supplementary information (ESI) available: Experimental procedures and characterization data for all compounds, copies of NMR spectra, and crystallographic data. CCDC [CCDC-1589617 (2a), CCDC-1589618 (3a), CCDC-1589619 (4a), CCDC-1589620 (5a)]. For ESI and crystallographic data in CIF or other electronic format see DOI: 10.1039/c7ra13343j functionalized isoxazoles from $\beta$-enamino diketone and hydroxylamine. The $\beta$-enamino diketones have been employed as precursors in functionalized heterocycles synthesis due to their excellent 1,3-dielectrophilic system, and in general they allow better control of regioselectivity. ${ }^{6}$

Over time, we have developed regioselective synthetic methodologies for the synthesis of multifunctionalized heterocycles from $\beta$-enamino diketones and different dinucleophiles. ${ }^{6}$ Variations in reaction conditions, ${ }^{6 e}$ Lewis acid, ${ }^{6 f}$ and $\beta$-enamino diketone structure ${ }^{6 e f}$ have resulted in regiochemical control of pyrazoles, ${ }^{\boldsymbol{6} \boldsymbol{a - c}, \boldsymbol{e}, \boldsymbol{f}}$ pyrazolo-pyridazinones, ${ }^{\boldsymbol{b} \boldsymbol{b}, \boldsymbol{c}}$ pyrimidines, ${ }^{\boldsymbol{6} \boldsymbol{d}}$ and their derivatives. Thus, we believe that the enamino diketones are potential precursors for the regioselective synthesis of functionalized isoxazoles by cyclocondensation with hydroxylamine. To our knowledge, there is only a single report in the literature regarding isoxazole synthesis from enamino diketone and hydroxylamine, where the authors have used a symmetrical $\beta$-enamino diketone. ${ }^{7}$

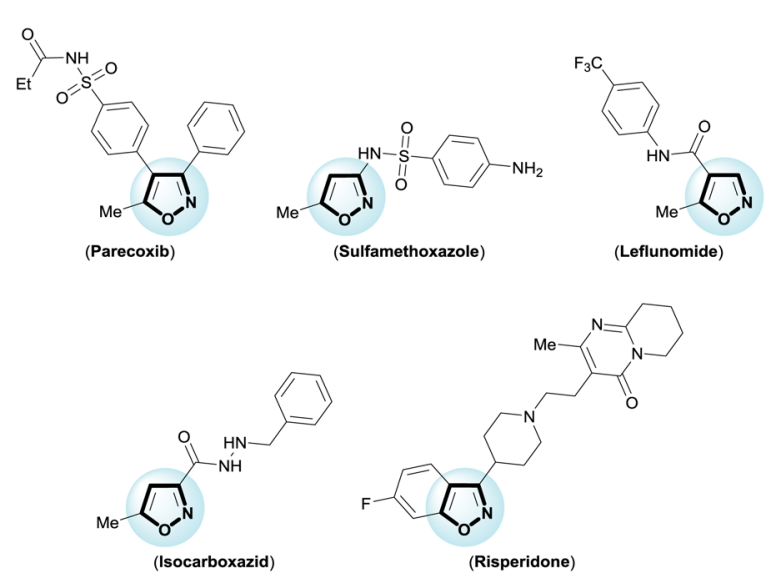

Fig. 1 Examples of medicinal products with the isoxazole moiety. 


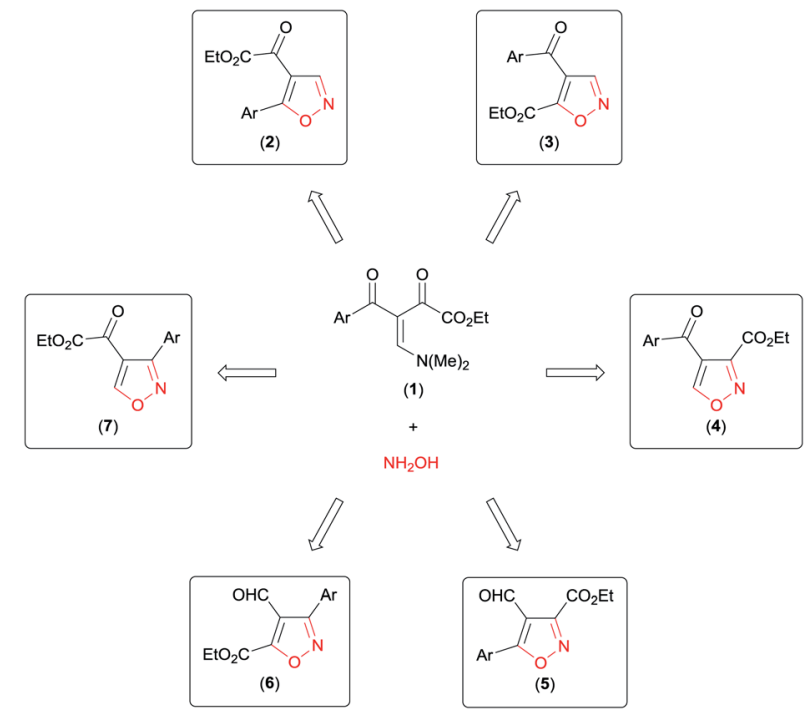

Scheme 1 Possible regioisomer isoxazoles obtained by cyclocondensation of $\beta$-enamino diketone with hydroxylamine.

Furthermore, a study of reactivity of the $\beta$-enamino diketone system with hydroxylamine has not yet been reported.

Analysing the reactive potential of the $\beta$-enamino diketone precursor in the cyclocondensation reaction with hydroxylamine, we observed that it would lead to formation of six regioisomer isoxazoles (Scheme 1). Thus, continuing our interest in this area, we report herein four methodologies to obtain functionalized 4,5-disubstituted isoxazoles, 3,4disubstituted isoxazoles, and 3,4,5-trisubstituted isoxazoles by regiochemical control of the cyclocondensation reaction of $\beta$-enamino diketones with hydroxylamine.

\section{Results and discussion}

We began this study using the $\beta$-enamino diketone $\mathbf{1 a}^{\mathbf{8}}$ and hydroxylamine hydrochloride $\left(\mathrm{NH}_{2} \mathrm{OH} \cdot \mathrm{HCl}\right)$ as model substrates (Table 1). Gratifyingly, in EtOH at room temperature, these substrates performed well, leading to a regioisomeric mixture of the 4,5-disubstituted isoxazoles 2a and 3a with selectivity favouring $\mathbf{3 a}$ in good yield (Table 1 , entry 1 ). The structure of $2 \mathbf{a}$ and 3a were established by NMR spectral data and unambiguously confirmed by X-ray crystallography ${ }^{9 a, b}$ (see Fig. SI 1 and 2 for full details, ESI $\dagger$ ). Encouraged by these results, other reaction conditions were investigated (Table 1). First, based on data recently reported by Souza et al., ${ }^{\text {ee }}$ we examined MeCN and the mixture $\mathrm{H}_{2} \mathrm{O} / \mathrm{EtOH}(1: 1)$ as solvents in the reaction of $1 \mathrm{a}$ with $\mathrm{NH}_{2} \mathrm{OH} \cdot \mathrm{HCl}$ (Table 1 , entries 2 and 3). The use of the aprotic polar solvent MeCN resulted in 2a as the main product in good yield (Table 1, entry 2).

On the other hand, the protic polar solvents mixture $\mathrm{H}_{2} \mathrm{O} / \mathrm{EtOH}$ yielded 3a as the main product (Table 1, entry 3), but this solvent was found to be less regioselective than EtOH (Table 1, entry 1). Next, we examined the reaction mediated by bases at room temperature (Table 1, entries 4-7, 10 and 11). Interestingly, only pyridine was compatible with the reaction, favouring the regioselective formation of 2a in EtOH and mainly in MeCN (Table 1,
Table 1 Optimization of reaction conditions of 1a with $\mathrm{NH}_{2} \mathrm{OH} \cdot \mathrm{HCl}$ to access 4,5-disubstituted isoxazoles regioisomers $2 a$ and $3 a$ regioselectively ${ }^{a}$

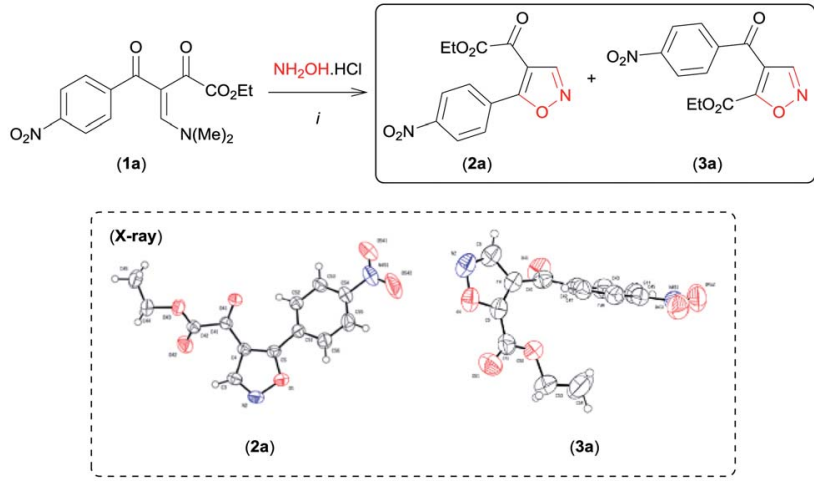

\begin{tabular}{|c|c|c|c|c|c|c|}
\hline \multirow[b]{2}{*}{ Entry } & \multicolumn{3}{|l|}{$i$} & \multicolumn{2}{|c|}{$\begin{array}{l}\text { Ratio }^{b} \\
(\%)\end{array}$} & \multirow[b]{2}{*}{ Yield $^{c}(\%)$} \\
\hline & Solvent & Base & Time (h)/Temp. $\left({ }^{\circ} \mathrm{C}\right)$ & $2 a$ & $3 a$ & \\
\hline 1 & EtOH & - & $10 / 25$ & 35 & 65 & 73 \\
\hline 2 & MeCN & - & $16 / 25$ & 65 & 35 & 81 \\
\hline 3 & $\mathrm{EtOH} / \mathrm{H}_{2} \mathrm{O}$ & - & $10 / 25$ & 40 & 60 & 68 \\
\hline 4 & EtOH & Py & $2 / 25$ & 64 & 36 & 71 \\
\hline 5 & MeCN & Py & $2 / 25$ & 76 & 24 & 87 \\
\hline 6 & $\mathrm{MeCN}$ & DBU & $2 / 25$ & $-^{d}$ & & - \\
\hline 7 & MeCN & $\mathrm{K}_{2} \mathrm{CO}_{3}$ & $2 / 25$ & $-^{d}$ & & - \\
\hline 8 & EtOH & - & 1/reflux & 23 & 77 & 76 \\
\hline 9 & MeCN & - & 3/reflux & 54 & 46 & 78 \\
\hline 10 & MeCN & Py & 1/reflux & 45 & 55 & 80 \\
\hline 11 & EtOH & Py & 1/reflux & 62 & 38 & 74 \\
\hline
\end{tabular}

${ }^{a}$ Reaction conditions: $1 \mathrm{a}(0.5 \mathrm{mmol}), \mathrm{NH}_{2} \mathrm{OH} \cdot \mathrm{HCl}(0.6 \mathrm{mmol}, 1.2$ equiv.), base ( $0.6 \mathrm{mmol}, 1.2$ equiv.), solvent $(4 \mathrm{~mL}) .{ }^{b}$ Calculated from the ${ }^{1} \mathrm{H}$-NMR spectrum of crude product. ${ }^{c}$ Isolated yield (regioisomeric mixture). ${ }^{d} \mathbf{2 a}$ and $\mathbf{3 a}$ as intractable mixtures of several products.

entries 4 and 5). The reactions of other bases led to the formation of $\mathbf{2 a}$ and $\mathbf{3} \mathbf{a}$ as intractable mixtures of several products (Table 1 , entries 6 and 7). Finally, by reacting $1 \mathrm{a}$ with $\mathrm{NH}_{2} \mathrm{OH} \cdot \mathrm{HCl}$ in EtOH at reflux, 3a was formed with higher regioselectivity (Table 1, entry 8) than at room temperature (Table 1 , entry 1 ). In contrast, varying the reaction temperature in $\mathrm{MeCN}$ we discovered that increasing the temperature can jeopardize the regioselectivity of the reaction (Table 1, entry 9). In general, regioisomer 2a was favoured in MeCN with pyridine at room temperature (Table 1, entry 5), whereas 3a was preferentially formed in EtOH at reflux (Table 1, entry 8).

Having established the reaction conditions for synthesis of both regioisomeric 4,5-disubstituted isoxazoles 2a and 3a with moderate regioselectivity, we became interested in reversing the reactivity of the $\beta$-enamino diketone 1a toward hydroxylamine hydrochloride by varying the reaction conditions, so as to access 3,4-disubstituted isoxazoles regioselectively. To our surprise, when 1a was reacted with $\mathrm{NH}_{2} \mathrm{OH} \cdot \mathrm{HCl}$ in the presence of the Lewis acid carbonyl activator $\mathrm{BF}_{3}\left(\mathrm{BF}_{3} \cdot \mathrm{OEt}_{2}\right)$ (0.5 equiv.) in $\mathrm{MeCN}$ at room temperature, the desired 3,4-disubstituted isoxazole 4a was formed as the main product (Table 2, entry 1). The 
structure of 4a was unambiguously established from its spectral and X-ray crystallographic data ${ }^{9 c}$ (see Fig. SI 3 for full details, ESI $\dagger$ ).

By optimization of reaction conditions using this protocol, we observed that regioselectivity for the formation of isoxazole 4a was dependent on the amount of $\mathrm{BF}_{3}$ (Table 2, entries 1-4) and the solvent used (Table 2, entries 5 and 6). We obtained $4 a$ with high regioselectivity (90\%) in good yield (79\%) employing 2 equivalents of $\mathrm{BF}_{3}$ in $\mathrm{MeCN}$ with pyridine at room temperature (Table 2, entry 5). The by-product mixed with $\mathbf{4 a}$ under these conditions (Table 2, entry 5) was isolated and characterized as 3,5-disubstituted 4-formyl-isoxazole 5a based on NMR spectral analysis and single crystal X-ray analysis ${ }^{9 d}$ (see Fig. SI 4 for full details, ESI $\dagger$ ).

On the basis of these observations, we have devoted our efforts to developing a methodology which allows to access 5 a regioselectively. According to the data recently reported by da Silva et al. ${ }^{\text {of }}$ the presence of an aminoalkyl secondary group with high steric demand (i-PrNH- or $t$-BuNH-) bound to the $\beta$-carbon of the $\beta$-enamino diketone system in combination with the Lewis acid carbonyl activator $\mathrm{BF}_{3}$ provides conditions for the regiocontrolled reaction of $\beta$-enamino diketones with aryl hydrazines to give 3,5disubstituted 4-formyl- $N$-arylpyrazoles with high regioselectivity. Thus, we tested the viability of this approach for the regioselective preparation of 3,5-disubstituted 4-formyl-isoxazole 5a. When we tested the reaction of $\beta$-enamino diketone $6 \mathbf{a}$ (ref. $6 f$ ) (1.0 equiv.), prepared from $1 \mathrm{a}$ (ref. 8) (Scheme 2), with $\mathrm{NH}_{2}$ $\mathrm{OH} \cdot \mathrm{HCl}$ (1.2 equiv.) in $\mathrm{MeCN}$ and $\mathrm{BF}_{3} \cdot \mathrm{OEt}_{2}$ (2.0 equiv.) at reflux for $1 \mathrm{~h}$, the desired isoxazole 5a was obtained with 100\% regioselectivity and in good yield (80\%) (Scheme 2, ROUTE I).

Subsequently, the efficiency of this protocol was further improved by developing a sequential one-pot procedure to
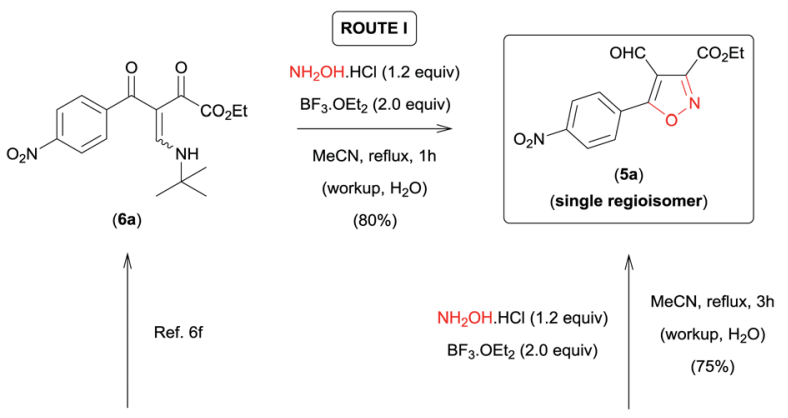

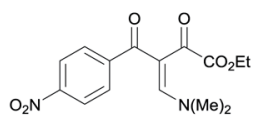

(1a)

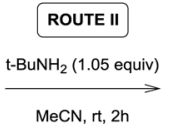

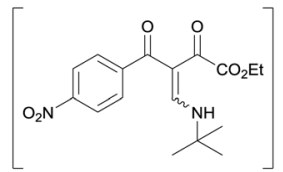

(6a)
Scheme 2 ROUTE I - Synthesis of 3,5-disubstituted 4-formyl-isoxazol 5 a from $\beta$-enamino diketone $6 a$; ROUTE II - sequential one-pot procedure to obtain 5 a from $\beta$-enamino diketone $1 \mathrm{a}$.

obtain isoxazole $\mathbf{5 a}$ directly from the $\beta$-enamino diketone $\mathbf{1 a}$ (Scheme 2, ROUTE II). The best results for this procedure were obtained by in situ generation of the $\beta$-enamino diketone precursor 6a from treatment of 1a with tert-butylamine (1.05 equiv.) in $\mathrm{MeCN}$ at room temperature for $2 \mathrm{~h}$, followed by the addition of $\mathrm{NH}_{2} \mathrm{OH} \cdot \mathrm{HCl}$ (1.2 equiv.) and $\mathrm{BF}_{3} \cdot \mathrm{OEt}_{2}$ (2.0 equiv.) under reflux of MeCN for $3 \mathrm{~h}$ (Scheme 2, ROUTE II). Through this procedure 5a was also obtained with $100 \%$ regioselectivity and a similar yield when prepared directly from the $\beta$-enamino diketone precursor 6a (Scheme 2, ROUTE I).

Having in hand the optimal reaction conditions to access 4,5-disubstituted (regioisomers $2 \mathbf{a}$ and 3a, Table 1, entries 5 and

Table 2 Optimization of reaction conditions of $1 \mathrm{a}$ with $\mathrm{NH}_{2} \mathrm{OH} \cdot \mathrm{HCl}$ mediated by $\mathrm{BF}_{3} \cdot \mathrm{OEt}_{2}$ to access 3,4-disubstituted isoxazole 4 a regioselectively ${ }^{a}$

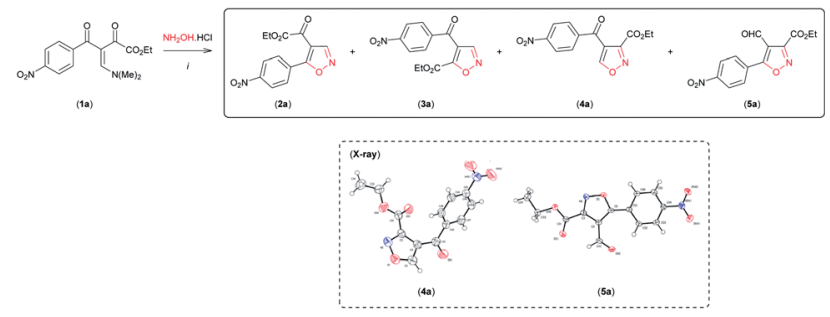

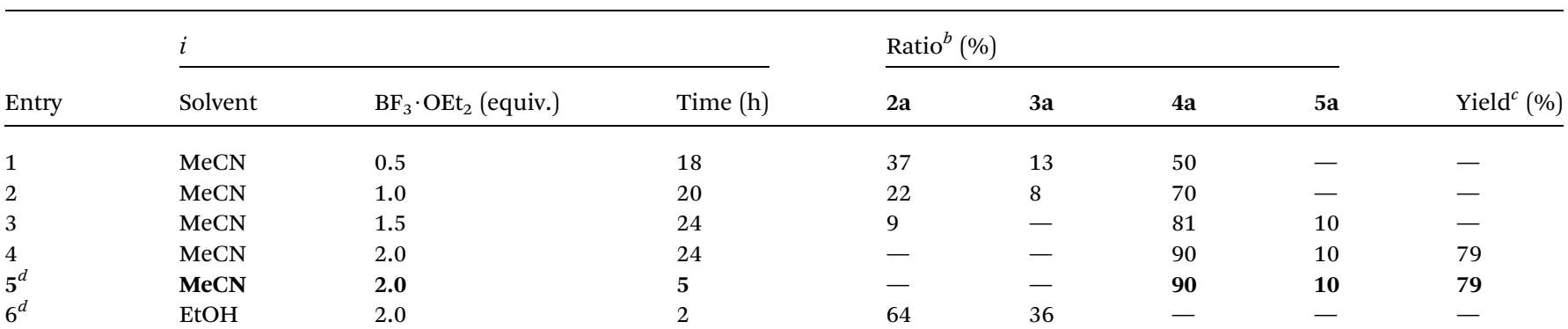

${ }^{a}$ Reaction conditions: $1 \mathrm{a}(0.5 \mathrm{mmol}), \mathrm{NH}_{2} \mathrm{OH} \cdot \mathrm{HCl}(0.6 \mathrm{mmol}, 1.2$ equiv. $)$, room temperature, solvent $(4 \mathrm{~mL}) .{ }^{b} \mathrm{Calculated}$ from the ${ }^{1} \mathrm{H}-\mathrm{NMR}$ spectrum of crude product. ${ }^{c}$ Isolated yield (regioisomeric mixture). ${ }^{d}$ Pyridine (1.4 equiv.). 
8, respectively), 3,4-disubstituted (regioisomer 4a, Table 2, entry 5), and 3,5-disubstituted 4-formyl (regioisomer 5a, Scheme 2, ROUTE II) isoxazoles regioselectively from $\beta$-enamino diketone 1a and $\mathrm{NH}_{2} \mathrm{OH} \cdot \mathrm{HCl}$, we examined the scope of this reaction under the conditions reported above, varying the electronic properties of the $\beta$-enamino diketone substrate 1 . The results are summarized in Table 3.

Similar to the $\beta$-enamino diketone substrate 1a (Table 3, entries 1, 6, 11 and 16), all substrates examined (1b-e) were found to undergo the desired transformation to give the

Table 3 Substrate scope ${ }^{a}$

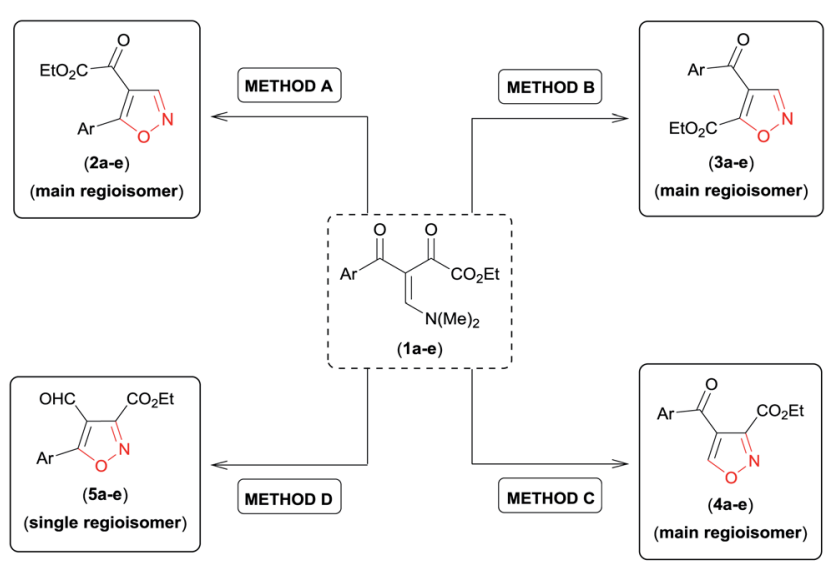

METHOD A: $\mathrm{NH}_{2} \mathrm{OH} . \mathrm{HCl}$ (1.2 equiv), Py (1.2 equiv), MeCN, $\mathrm{rt}$, 2h.

METHOD B: $\mathrm{NH}_{2} \mathrm{OH} . \mathrm{HCl}$ (1.2 equiv), EtOH, reflux, $1 \mathrm{~h}$.

METHOD C: $\mathrm{NH}_{2} \mathrm{OH} . \mathrm{HCl}$ (1.2 equiv), Py (1.4 equiv), $\mathrm{BF}_{3} . \mathrm{OEt}_{2}$ (2.0 equiv), MeCN, $\mathrm{rt}, 5 \mathrm{~h}$.

METHOD D: (1) t-BuNH ${ }_{2}$ (1.05 equiv), MeCN, rt, $2 \mathrm{~h}$; (2) $\mathrm{NH}_{2} \mathrm{OH} . \mathrm{HCl}$ (1.2 equiv), $\mathrm{BF}_{3} . \mathrm{OEt}_{2}$ (2.0 equiv), $\mathrm{MeCN}$, reflux, $3 \mathrm{~h}$ (3) Workup, $\mathrm{H}_{2} \mathrm{O}$.

\begin{tabular}{|c|c|c|c|c|}
\hline Entry & Substrate (Ar) & Method & Ratio $^{b}(\%)$ & Yield $^{c}(\%)$ \\
\hline 1 & $1 \mathbf{a}\left(4-\mathrm{NO}_{2} \mathrm{C}_{6} \mathrm{H}_{4}\right)$ & A & $\mathbf{2 a}(76), \mathbf{3 a}(24)$ & $87(65)$ \\
\hline 2 & $1 \mathbf{b}\left(4-\mathrm{FC}_{6} \mathrm{H}_{4}\right)$ & A & $2 \mathbf{b}(62), 3 \mathbf{b}(38)$ & $88(53)$ \\
\hline 3 & 1c $(\mathrm{Ph})$ & A & $2 \mathrm{c}(65), 3 \mathbf{c}(35)$ & $89(57)$ \\
\hline 4 & 1d $\left(4-\mathrm{MeC}_{6} \mathrm{H}_{4}\right)$ & A & $2 \mathrm{~d}(60), 3 \mathrm{~d}(40)$ & $90(52)$ \\
\hline 5 & $1 \mathrm{e}\left(4-\mathrm{OMeC}_{6} \mathrm{H}_{4}\right)$ & A & $2 \mathrm{e}(58), 3 \mathbf{e}(42)$ & $90(50)$ \\
\hline 6 & $1 \mathrm{a}\left(4-\mathrm{NO}_{2} \mathrm{C}_{6} \mathrm{H}_{4}\right)$ & B & $\mathbf{2 a}(23), 3 \mathbf{a}(77)$ & $76(58)$ \\
\hline 7 & $1 \mathbf{b}\left(4-\mathrm{FC}_{6} \mathrm{H}_{4}\right)$ & B & $2 \mathbf{b}(20), 3 \mathbf{b}(80)$ & $82(65)$ \\
\hline 8 & 1c $(\mathrm{Ph})$ & B & $2 \mathbf{c}(20), 3 \mathbf{c}(80)$ & $81(64)$ \\
\hline 9 & $1 d\left(4-\mathrm{MeC}_{6} \mathrm{H}_{4}\right)$ & B & $2 \mathbf{d}(20), 3 \mathbf{d}(80)$ & $81(63)$ \\
\hline 10 & $1 \mathrm{e}\left(4-\mathrm{OMeC}_{6} \mathrm{H}_{4}\right)$ & B & $2 \mathrm{e}(35), 3 \mathrm{e}(65)$ & $83(52)$ \\
\hline 11 & $1 \mathbf{a}\left(4-\mathrm{NO}_{2} \mathrm{C}_{6} \mathrm{H}_{4}\right)$ & $\mathrm{C}$ & $\mathbf{4 a}(90), 5 a(10)$ & $79(70)$ \\
\hline 12 & $\mathbf{1 b}\left(4-\mathrm{FC}_{6} \mathrm{H}_{4}\right)$ & $\mathrm{C}$ & $\mathbf{4 b}(90), \mathbf{5 b}(10)$ & $81(71)$ \\
\hline 13 & 1c $(\mathrm{Ph})$ & $\mathrm{C}$ & $4 c(90), 5 c(10)$ & $72(64)$ \\
\hline 14 & 1d $\left(4-\mathrm{MeC}_{6} \mathrm{H}_{4}\right)$ & $\mathrm{C}$ & $4 d(90), 5 d(10)$ & $73(65)$ \\
\hline 15 & 1e $\left(4-\mathrm{OMeC}_{6} \mathrm{H}_{4}\right)$ & $\mathrm{C}$ & $4 \mathbf{e}(90), 5 \mathbf{e}(10)$ & $83(74)$ \\
\hline 16 & $1 \mathbf{a}\left(4-\mathrm{NO}_{2} \mathrm{C}_{6} \mathrm{H}_{4}\right)$ & D & $5 \mathbf{a}(100)$ & (75) \\
\hline 17 & $1 \mathbf{b}\left(4-\mathrm{FC}_{6} \mathrm{H}_{4}\right)$ & D & $5 \mathbf{b}(100)$ & (65) \\
\hline 18 & 1c $(\mathrm{Ph})$ & $\mathrm{D}$ & $5 c(100)$ & $(62)$ \\
\hline 19 & 1d $\left(4-\mathrm{MeC}_{6} \mathrm{H}_{4}\right)$ & $\mathrm{D}$ & $5 d(100)$ & (70) \\
\hline 20 & $1 \mathrm{e}\left(4-\mathrm{OMeC}_{6} \mathrm{H}_{4}\right)$ & $\mathrm{D}$ & $5 e(100)$ & (68) \\
\hline
\end{tabular}

${ }^{a}$ Reaction conditions: 1 b-e $(0.5 \mathrm{mmol}), \mathrm{NH}_{2} \mathrm{OH} \cdot \mathrm{HCl}(0.6 \mathrm{mmol}, 1.2$ equiv.), solvent $(4 \mathrm{~mL}) .{ }^{b}$ Calculated from the ${ }^{1} \mathrm{H}-\mathrm{NMR}$ spectrum of crude product. ${ }^{c}$ Isolated yields (regioisomeric mixture); yields in parentheses are yields of the main regioisomer isolation by column chromatography. corresponding products in good to excellent yields (62-90\%) (Table 3, entries $2-5,7-10,12-15$, and 17-20). In general, the electronic nature of the Ar substituent on the $\beta$-enamino diketone 1a-e imposed a small effect on the regioselectivity of the reaction for methods A and B. For method A, the substrate bearing the stronger $p$-OMe (1e) electron-donating substituent provided low regioselectivity for the formation of the isoxazole regioisomer 2 (Table 3, entry 5), while the $p-\mathrm{NO}_{2}$ electron-withdrawing substituent provided high regioselectivity (Table 3 , entry 1 ). For the other substituents (Table 3, entries 2-4), regioisomer 2 was obtained with moderate regioselectivity. On the other hand, for method B we did not see a clear correlation of the electronic nature of the substituents (Ar) with the regioselectivity of the formation of isoxazole 3 (Table 3, entries 6-10). In contrast, regardless of the different electronic properties of the $\mathrm{Ar}$ substituent on $\beta$-enamino diketone 1a-e, isoxazoles regioisomer $\mathbf{4}$ and $\mathbf{5}$ were always obtained with high regioselectivity (Table 3, entries 11-20).

Finally, through detailed analysis of the NMR spectral data of the new isoxazoles reported here, we observed that difference in the chemical shifts of ${ }^{1} \mathrm{H}$ and ${ }^{13} \mathrm{C}$ allow a simple assignment of the different regioisomeric forms obtained. For example, we use isoxazoles $\mathbf{2 a}, \mathbf{3 a}, \mathbf{4 a}$, and $\mathbf{5 a}$ as a model to show these differences (Fig. 2).

For the disubstituted isoxazoles $\mathbf{2 a}, \mathbf{3 a}$, and $\mathbf{4 a}$, the hydrogen atom attached to the isoxazole nucleus ( $\mathrm{H} 3$ for $\mathbf{2 a}$ and $3 \mathbf{3 a}, \mathrm{H} 5$ for 4a - Fig. 2) have notable differences in the chemical shifts of ${ }^{1} \mathrm{H}$ NMR spectrum. The $\mathrm{H} 3$ atom in $3 \mathrm{a}(8.59 \mathrm{ppm})$ is more shielded than the $\mathrm{H} 5$ atom in $\mathbf{4 a}(8.89 \mathrm{ppm})$ by a difference of approximately 0.30 ppm, whereas $\mathrm{H} 5$ (4a) is more shielded than the H3 atom in $2 \mathrm{a}(9.12 \mathrm{ppm})$ by about $0.23 \mathrm{ppm}$ (Fig. 2). With regard to ${ }^{13} \mathrm{C}$ NMR spectra of disubstituted isoxazoles, the major differences between the chemical shifts of the 4,5 (2a and 3a) and the 3,4 (4a)-disubstituted regioisomers are related to the carbon atoms C3 in 2a and 3a, and C5 in $\mathbf{4 a}$ (Fig. 2). This is because the C5 atom signal (compound $\mathbf{4 a}$ ) is approximately 10 ppm more deshielded than the corresponding atom (C3) in 2a and 3a (Fig. 2). For the 4,5-disubstituted regioisomers $\mathbf{2 a}$ and $\mathbf{3 a}$, the signal of the ketone carbonyl attached at the 4-position of the isoxazole ring shows considerable differences in the chemical shifts of the ${ }^{13} \mathrm{C}$ NMR spectrum, because the ketone carbonyl signal in $\mathbf{2 a}$ is more shielded than the ketone carbonyl in $\mathbf{3 a}$ by

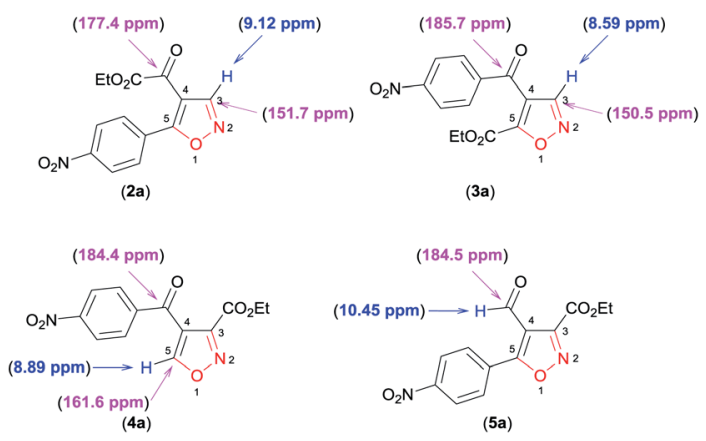

Fig. $2{ }^{1} \mathrm{H}$ and ${ }^{13} \mathrm{C}$ NMR chemical shifts of the regioisomers $2 \mathrm{a}, 3 \mathrm{a}, 4 \mathrm{a}$, and $5 \mathrm{a}$. 
about 8.3 ppm (Fig. 2). Unambiguously, 3,5-disubstituted 4formyl isoxazole 5a could be identified by the characteristic chemical shifts of aldehyde hydrogen and carbon of the ${ }^{1} \mathrm{H}$ and ${ }^{13}$ C NMR spectra (Fig. 2).

\section{Conclusions}

In summary, we have developed four methodologies for the regioselective synthesis of polyfunctionalized isoxazoles by cyclocondensation of $\beta$-enamino diketones with hydroxylamine. The regiochemistry of the reaction has been controlled by: the solvent; use of pyridine; the Lewis acid carbonyl activator $\mathrm{BF}_{3}$; and the structure of the $\beta$-enamino diketone. These variations allowed access to four of the six possible regioisomer isoxazoles with good yields, which have different substitution patterns: 3,4-disubstituted, 4,5-disubstituted-, and 3,4,5-trisubstituted isoxazoles.

\section{Conflicts of interest}

There are no conflicts to declare.

\section{Acknowledgements}

The authors are grateful for the financial support from CNPq/ Brazil (CNPq/Universal Process No. 45920/2014-8) and Fundação Araucária/Brazil. Fellowships from CAPES/Brazil are also acknowledged.

\section{Notes and references}

1 (a) C. J. Forsyth, F. Ahmed, R. D. Cink and C. S. Lee, J. Am. Chem. Soc., 1998, 120, 5597; (b) M. P. Giovannoni, C. Vergelli, C. Ghelardini, N. Galeotti, A. Bartolini and V. DalPiaz, J. Med. Chem., 2003, 46, 1055; (c) A. W. G. Burgett, Q. Li, Q. Wei and P. G. Harran, Angew. Chem., Int. Ed., 2003, 42, 4961; (d) W. F. Kean, Curr. Med. Res. Opin., 2004, 20, 1275; (e) W. T. Li, D. R. Hwang, C. P. Chen, C. W. Shen, C. L. Huang, T. W. Chen, C. H. Lin, Y. L. Chang, Y. Y. Chang, Y. K. Lo, H. Y. Tseng, C. C. Lin, J. S. Song, H. C. Chen, S. J. Chen, S. H. Wu and C. T. Chen, J. Med. Chem., 2003, 46, 1706; (f) N. D. Argade, B. K. Kalrale and C. H. Gill, Eur. J. Chem., 2008, 5, 120; $(g)$ C. K. Ryu, R. Y. Lee, N. Y. Kim, Y. H. Kim and A. L. Song, Bioorg. Med. Chem. Lett., 2009, 19, 5924; (h) L. F. Yu, J. B. Eaton, A. Fedolak, H. K. Zhang, T. Hanania, D. Brunner, R. J. Lukas and A. P. Kozikowski, J. Med. Chem., 2012, 55, 9998; (i) P. D. Lokhande, K. Hasanzadeh, H. Khaledi and H. M. Ali, Monatsh. Chem., 2013, 144, 237; (j) M. M. Bassaco, M. P. Fortes, D. F. Back, T. S. Kaufman and C. C. Silveira, $R S C A d v$. 2014, 4, 60785; (k) A. K. Ghosh, J. Takayama, L. A. Kassekert, J.-R. Ella-Menye, S. Yashchuk, J. Agniswamy, Y.-F. Wang, M. Aoki, M. Amano, I. T. Weber and H. Mitsuya, Bioorg. Med. Chem. Lett., 2015, 25, 4903; (l) E. Azzali, D. Machado, A. Kaushik, F. Vacondio, S. Flisi, C. S. Cabassi, G. Lamichhane, M. Viveiros, G. Costantino and M. Pieroni, J. Med. Chem., 2017, 60, 7108.
2 (a) D. P. Curran, J. Am. Chem. Soc., 1983, 105, 5826; (b) P. G. Baraldi, A. Barco, S. Benetti, G. P. Pollini and D. Simon, Synthesis, 1987, 857; (c) M. G. Charest, C. D. Lerner, J. D. Brubaker, D. R. Siegel and A. G. Myers, Science, 2005, 308, 395; (d) M. G. Charest, D. R. Siegel and A. G. Myers, J. Am. Chem. Soc., 2005, 127, 8292; (e) J. D. Brubaker and A. G. Myers, Org. Lett., 2007, 9, 3523; $(f)$ C. Sun, Q. Wang, J. D. Brubaker, P. M. Wright, C. D. Lerner, K. Noson, M. Charest, D. R. Siegel, Y. M. Wang and A. G. Myers, J. Am. Chem. Soc., 2008, 130, 17913; $(g)$ D. A. Kummer, D. Li, A. Dion and A. G. Myers, Chem. Sci., 2011, 2, 1710; (h) P. M. Wright and A. G. Myers, Tetrahedron, 2011, 67, 9853; (i) F. Hu and M. Szostak, Adv. Synth. Catal., 2015, 357, 2583.

3 (a) T. M. V. Pinho e Melo, Curr. Org. Chem., 2005, 9, 925; (b) F. Hua and M. Szostaka, Adv. Synth. Catal., 2015, 357, 2583.

4 (a) V. V. Rostovtsev, L. G. Green, V. V. Fokin and K. B. Sharpless, Angew. Chem., 2002, 114, 2708; (b) F. Himo, T. Lovell, R. Hilgraf, V. V. Rostovtsev, L. Noodleman, K. B. Sharpless and V. V. Fokin, J. Am. Chem. Soc., 2005, 127, 210; (c) T. V. Hansen, P. Wu and V. V. Fokin, J. Org. Chem., 2005, 70, 7761; (d) H. Li, L. Yu, X. Zhang, W. L. Johnson, R. Figueroa and R. P. Hsung, Heterocycles, 2007, 74, 553; (e) M. Meldal and C. W. Tornoe, Chem. Rev., 2008, 108, 2952; $(f)$ J. E. Hein and V. V. Fokin, Chem. Soc. Rev., 2010, 39, 1302.

5 (a) L. Claisen and O. Lowman, Chem. Ber., 1888, 1149; (b) B. Iddon, Heterocycles, 1994, 37, 1263; (c) A. Pace, S. Buscemi and N. Vivona, Org. Prep. Proced., 2007, 39, 1; (d) N. T. Patil and Y. Yamamoto, Chem. Rev., 2008, 108, 3395; (e) T. M. V. D. Pinho e Melo, Eur. J. Org. Chem., 2010, 3363; (f) F. Heaney, Eur. J. Org. Chem., 2012, 3043; (g) T. Lu and F. Hu, Synthesis, 2012, 44, 2805; (h) W. S. Hamama, M. E. Ibrahim and H. H. Zoorob, Synth. Commun., 2013, 43, 2393; (i) A. V. Gulevich, A. S. Dudnik, N. Chernyak and V. Gevorgyan, Chem. Rev., 2013, 113, 3084; (j) S. Tang, J. He, Y. Sun, L. He and X. She, Org. Lett., 2009, 11, 3982; $(k)$ S. Tang, J. He, Y. Sun, L. He and X. She, J. Org. Chem., 2010, 75, 1961; (l) D. Xiang, X. Xin, X. Liu, R. Zhang, J. Yang and D. Dong, Org. Lett., 2012, 14, 644; $(m)$ S. Samai, T. Chanda, H. Ila and M. S. Singh, Eur. J. Org. Chem., 2013, 4026; (n) R. Harigae, K. Moriyama and H. Togo, J. Org. Chem., 2014, 79, 2049.

6 (a) F. A. Rosa, P. Machado, P. S. Vargas, H. G. Bonacorso, N. Zanatta and M. A. P. Martins, Synlett, 2008, 1673; (b) M. J. V. da Silva, R. G. M. Silva, U. Z. Melo, D. S. Gonçalves, D. F. Back, S. Moura, R. M. Pontes, E. A. Basso, G. F. Gauze and F. A. Rosa, $R S C A d v$., 2016, 6, 290; (c) A. P. Jacomini, M. J. V. da Silva, R. G. M. Silva, D. S. Gonçalves, H. Volpato, E. A. Basso, F. R. Paula, C. V. Nakamura, M. H. Sarragiotto and F. A. Rosa, Eur. J. Med. Chem., 2016, 124, 340; (d) D. S. Gonçalves, M. J. V. da Silva, T. F. Souza, A. P. Jacomini, D. F. Back, E. A. Basso, S. Moura and F. A. Rosa, Synthesis, 2016, 3042; (e) T. F. Souza, M. J. V. da Silva, R. G. M. Silva, D. S. Gonçalves, P. A. Simon, A. P. Jacomini, E. A. Basso, S. Moura, M. A. P. Martins, D. F. Back and F. A. Rosa, Asian J. Org. Chem., 2017, 6, 627; 
(f) M. J. V. da Silva, J. Poletto, A. P. Jacomini, K. E. Pianoski, D. S. Gonçalves, G. M. Ribeiro, S. M. de Souza Melo, D. F. Back, S. Moura and F. A. Rosa, J. Org. Chem., 2017, 82, 12590.

7 G. Li, K. Watson, R. W. Buckheit and Y. Zhang, Org. Lett., 2007, 9, 2043.
8 F. A. Rosa, P. Machado, M. Rossatto, P. S. Vargas, H. G. Bonacorso, N. Zanatta and M. A. P. Martins, Synlett, $2007,3165$.

9 (a) CCDC-1589617 (for 2a); (b) CCDC-1589618 (for 3a); (c) CCDC-1589619 (for 4a); (d) CCDC-1589620 (for 5a) contains the supplementary crystallographic data for this paper. $\dagger$ 